\title{
Influence of Coagulant Concentrate on Volatile components of Hard Cheese Made from Yak Milk
}

\author{
Xuemei Song, Qi Liang, Weibing Zhang, Yan Zhang, Yongqiang Ma \\ College of Food Science and Engineering, Gan Su Agricultural University, Gan Su, Lanzhou \\ Laboratory of Functional Dairy, Gan Su, Lanzhou
}

Keywords: Hard Cheese Made from Yak Milk; Coagulant Concentrate; SPME; GC-MS

\begin{abstract}
In order to investigate in influence of coagulant concentrate on volatile components of hard cheese made from yak milk cheese samples with half normal concentration of rennet( $0.5 \mathrm{X})$, normal concentration of rennet(X), 1.5 times normal concentration of rennet(1.5X)and with double concentration of rennet (2X ) were analyzed by SPME coupled with GC-MS. Main volatile components in different cheese made from yak milk included acids, alcohols and esters, followed by hydrocarbons. From $0.5 \mathrm{X}$ to $2 \mathrm{X}$, number and content of volatile compounds gradually decreased and tended to stabilization. Esters were the first most abundant group of compounds and most of the identified esters were ethyl esters. Alcohols were the second most abundant group of compounds with ethanol which existed in all cheeses and 3-methylbutanol which existed in all cheeses except for $0.5 \mathrm{X}$ cheese. Acids were the third most abundant group of compounds and from $0.5 \mathrm{X}$ to $2 \mathrm{X}$, acid species and content decreased. Only three volatile components were the same in the all of cheese and most of compounds are different among the cheese. Therefore, coagulant concentrate influenced on number and content of volatile components of hard cheese made from yak milk.
\end{abstract}

\section{Introduction}

The unique flavour of a cheese variety is the result of a complex balance among volatile and non-volatile chemical compounds originating during the ripening processfrom milk fat, protein and carbohydrates by coagulant, endogenous milk enzyme and starters. Its flavor is influenced by many factors such as process technology, milk origin, starters and rennet. The volatile substances of cheese are importance part of cheese's flavour and some of them are responsible for its aroma. Most cheese varieties contain similar volatile compounds but in different proportions. Such many different cheeses as Cheddar (Suriyaphan et al., 2001) and Camembert (Pionnier et al., 2002) have been extensively studied for their volatile components, usually by means of GC-MS. Prior to their GC-MS analysis, it is necessary to extract them from the cheese. Dynamic headspace techniques seem to be the most adequate for the sampling of volatile compounds in cheese since they allow a selective extraction under non-destructive conditions.

The coagulant used in cheese making has a dual role. The primary function is to coagulate milk to produce cheese curd. In addition, a small proportion of the coagulant is carried over into the cheese. This residual coagulant remains proteolytically active in most aged cheeses and plays an important role in the development of texture and flavor. The amount of coagulant retained in cheese varies with manufacturing conditions. Retention of chymosin is influenced by heat treatment of the cheese milk and cooking temperature during cheese making. Residual chymosin is highly dependent on the rate of acidification during manufacture, particularly the $\mathrm{pH}$ of the whey at draining (Holmes et al., 1977). As for most cheese varieties, the initial hydrolysis of caseins is caused by the coagulant and to a lesser extent by plasmin and perhaps somatic cell proteinases (e.g., cathepsin D), which results in the formation of large (water-insoluble) and intermediate-sized (water-soluble) peptides which are subsequently degraded by the coagulant and enzymes from the starter and non-starter flora of the cheese. The production of small peptides and FAA is caused by the action of microbial proteinases and peptidases. FAAs are thought to be important for the development of the characteristic flavor (Broome, et al., 1990).

Hard cheese made of yak milk is a rennet-set curd which is rich in nutrition and its flavor is 
special. Yu et al (2005) have previously reported volatile substances of white yak milk. Wang et al (2012)have investigated volatile components of Hard cheese made of yak milk ripened at $5{ }^{\circ} \mathrm{C}$ and at 6 months .However, rennet is a key enzyme in cheese making and is important in the formation of cheese flavor during the maturation. Therefore, the objectives of this study were to investigate the effect of different concentrations of rennet on the of volatile components e hard cheese made from yak milk during ripening.

\section{Material and Methods}

\subsection{Cheese Making}

According to the procedure described by Liu et al (2009), four batches of cheese were produced. Operation in detail was as follows. Cheeses were manufactured from pasteurized $\left(62^{\circ} \mathrm{C}, 30 \mathrm{~min}\right)$ yak milk. Milk was cooled to $32^{\circ} \mathrm{C}$ and a $1 \%$ starter culture (Lactobacillus bulgaricus, Streptococcus thermophilus) and $0.03 \%$ (wt/vol) of $\mathrm{CaCl} 2$ were added. Different amount of calf rennet (105U/g, Lanzhou, China) was added and coagulant took $40 \mathrm{~min}$ at $32^{\circ} \mathrm{C}$. The coagulum was cut into 8- to 10-mm cubes and the curd was drained, salted by dry salt for $2 \mathrm{~h}$, pressed, and packed into vacuum pouches, vacuum sealed. Cheeses were ripened in a climate incubator at $10^{\circ} \mathrm{C}$ and analyzed at 3 months of ripening.

To simplify the treatment names, cheeses were called with the abbreviated form of a name (0.5X to $2 \mathrm{X}$ ), indicating the different additive amount of coagulant, followed by $0.5 \mathrm{X}$ if cheeses were manufactured with half normal concentration of rennet, followed by $\mathrm{X}$ if cheeses were manufactured with 1.5 times normal concentration of rennet, followed by $1.2 \mathrm{X}$ if cheeses were manufactured with normal concentration of rennet, followed by $2 \mathrm{X}$ if cheeses were manufactured with double concentration of rennet.

\subsection{SPME-GC-MS analysis}

A sample of cheese ( $\sim 6 \mathrm{~g})$ was finely grated, immediately mixed with anhydrous sodium sulfate ( 1.5g)and put into the appropriate vessel. 0.5ul of hexanone was added as internal standard. SPME syringe needle (bearing a 2-cm fibre coated with 85um carboxen/PDMS on poly-dimethyl-siloxane bonded to a flexible fused silica core (Supelco, Bellefonte, PA, USA) was introduced. The container was then thermostatted at $60^{\circ} \mathrm{C}$ for $15 \mathrm{~min}$. The absorbed volatile analytes were then analyzed by GC-MS (Aglient, USA).

OV1701glass capillary column $(30 \mathrm{~m} \times 0.25 \mathrm{~mm} \times 0.50 \mu \mathrm{m})$; oven temperature programme: $35^{\circ} \mathrm{C}$ for $3 \mathrm{~min}, 4{ }^{\circ} \mathrm{C} / \mathrm{min}$ to $200^{\circ} \mathrm{C}$, then $10^{\circ} \mathrm{C} / \mathrm{min}$ to $240^{\circ} \mathrm{C}$ and $240^{\circ} \mathrm{C}$ for $2 \mathrm{~min}$; He carrier gas: $1 \mathrm{~mL} / \mathrm{min}$; injector temperature $250{ }^{\circ} \mathrm{C}$.The eluted compounds were identified by comparison with mass spectral database (NIST MS Search 2.0).

\section{Results and discussion}

3.1Evolution of volatile compounds in hard cheese made from yak Milk with different additive amount of coagulant

Total ion chromatogram of volatile components in cheese samples is shown in Fig. 1. Thirty-one compounds were identified in yak milk cheese. They included 4 acids, 5 alcohols, 1 aldehyde, 9 esters, 5 hydrocarbons and 2 phenolic compounds. 18 volatile compounds existed in the 0.5X cheese. With the increase of coagulant concentrate, number and content of volatile compounds gradually decreased and tended to stabilization. 


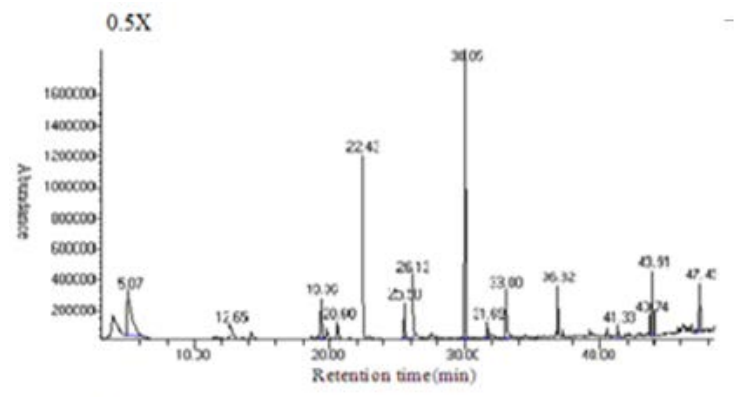

X
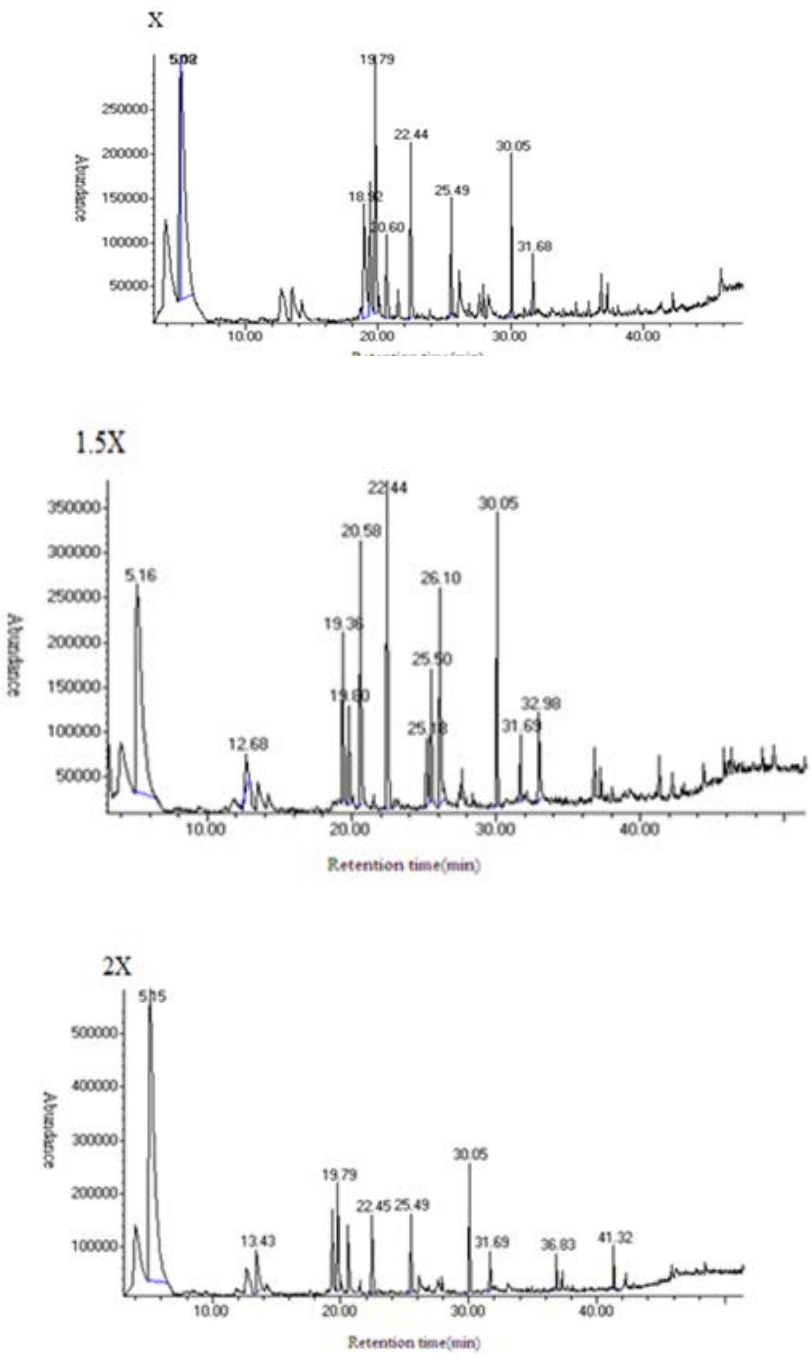

Figure 1 . Total ion chromatogram of volatile components in $0.5 \mathrm{X}, \mathrm{X}, 1.5 \mathrm{X}$ and $2 \mathrm{X}$ cheese samples 

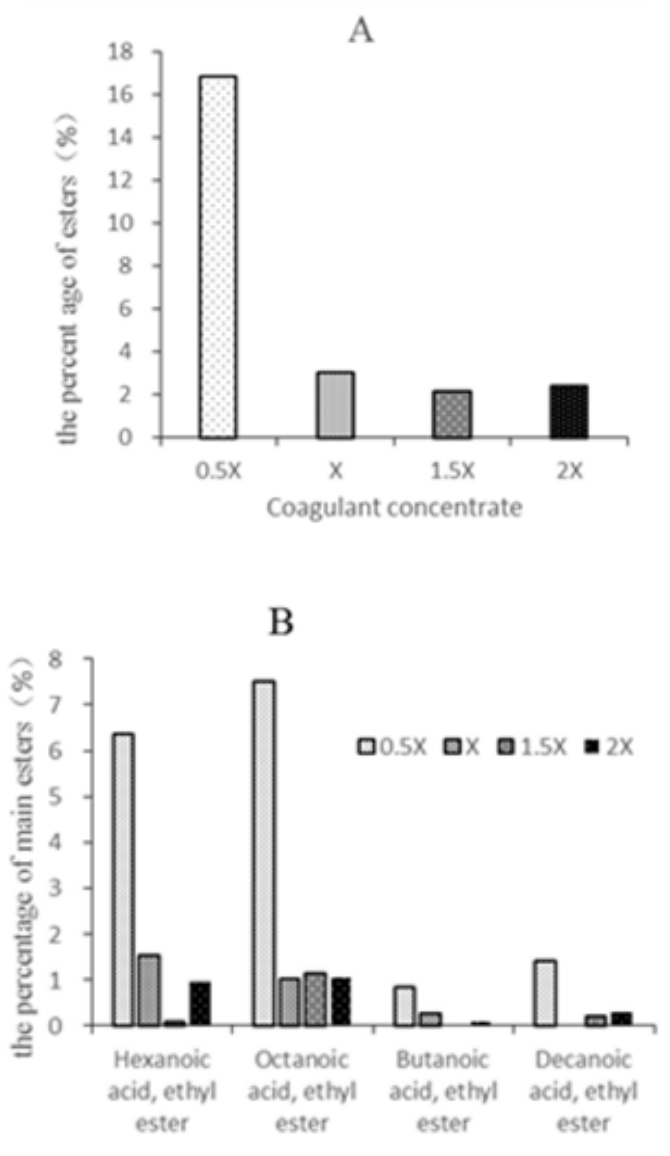

Figure 2. Influence of Coagulant Concentrate on esters in cheeses made from yak milk

Esters number was most among different cheeses. Ester found was Pentanoic acid, 2,2,4trimethyl-3-carboxyisopropyl isobutyl ester,3,6-Octadecadiynoic acid methyl ester, butanoic acidethyl ester, decanoic acid ethyl ester, octanoic acid ethyl ester, hexanoic acid ethyl ester, àhydroxy- benzeneacetic acid, 2-methyl-propanoic acid-ethyl ester. Esters, which are responsible for the fruity flavor in cheese, are formed through 2 enzymatic reactions, esterification and alcoholysis. Esterification is the formation of esters from alcohols and carboxylic acids, whereas alcoholysis is the production of esters from alcohols and acylglycerols or from alcohols or acyl-coenzyme A (Liu et al., 2004).The majority of the identified esters were ethyl esters, probably due to high quantities of ethanol.

Fig. 2 shows influence of coagulant concentrate on esters in cheeses made from yak milk. From $0.5 \mathrm{X}$ to $2 \mathrm{X}$, content of esters gradually fell. Content of esters in the $\mathrm{X} 、 1.5 \mathrm{X}$ and $2 \mathrm{X}$ cheese was similar and $2 \%-3 \%$ except $0.5 \mathrm{X}$ cheese. An excessive concentration has been reported to cause a defect in Cheddar cheese (Bills et al., 1965). So coagulant concentrate added was low, which led to cheese off - flavors.

\subsection{Influence of Coagulant Concentrate on alcohols of Hard Cheese Made from Yak Milk}

Alcohols are quantitatively the main chemical family found in the volatile fraction of hard cheese made from yak Milk with different additive amount of coagulant. Alcohols found in the yak milk were ethanol, 3-methyl-1-butanol, 2, 5-dimethyl-5-hexen-3-ol, 1-hexanol, 2-dimethyl- 1hexanol. Their concentrations did not differ among treatments. Fig. 3 shows influence of coagulant concentrate on alcohols and main alcohols in cheeses made from yak milk. Alcohol number was more in $\mathrm{X}$ cheese and it was few in $0.5 \mathrm{X}$ cheese. Compound number and species were similar in $\mathrm{X}$ and $2 \mathrm{X}$ cheese. Most alcohols are formed via oxidation. Lactococci and other lactic acid bacteria are able to produce ethanol from lactose. In addition to the alcohols in addition to the alcohols 
produced from amino acid catabolism (Centeno et al., 2002).
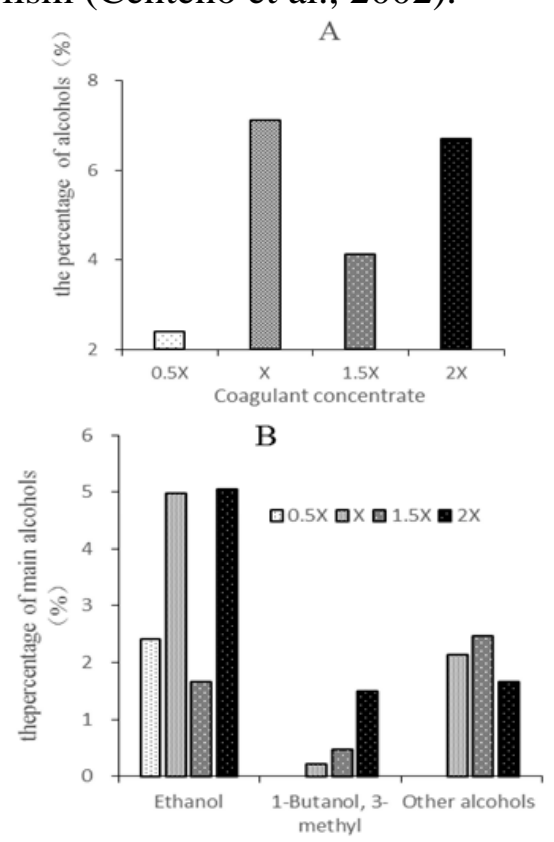

Figure 3. Influence of Coagulant Concentrate on alcohols and main alcohols in cheeses made from yak milk

3.4Influence of Coagulant Concentrate on Acids of Hard Cheese Made from Yak Milk during the Ripening

Acids, particularly short-chain fatty acids, are produced primarily by lipolysis. However, nbutanoic and ethanoic acids may also be produced by fermentation of lactose and lactic acid (Ortigosa et al., 2001). Deamination of amino acids and possibly lipid oxidation may also contribute to the overall acid pool. The contribution of acids to aroma development has been demonstrated in many matured cheese varieties (Ortigosa et al., 2001; Saldo et al., 2003; Barron et al., 2005).

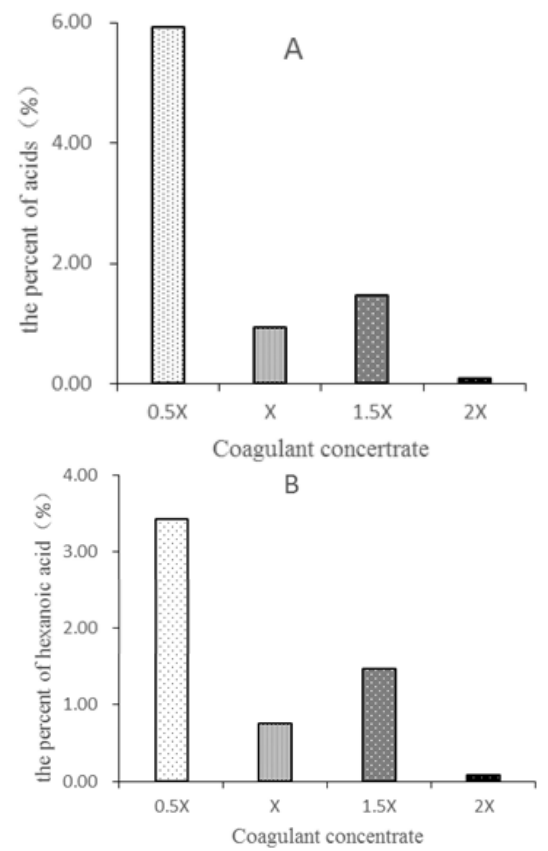

Figure 4. Influence of Coagulant Concentrate on Acids and Hexanoic acid in cheeses made from yak milk

Fig. 4 shows influence of coagulant concentrate on acids and hexanoic acid in cheeses made from yak milk. The number of acids was comparatively more in $0.5 \mathrm{X}$ cheese, its total content was 
high and its percentage was $5.92 \%$. From $0.5 \mathrm{X}$ to $2 \mathrm{X}$, the number and content of acids gradually fell. Lipoprotein lipases (80\%) are connected to casein micelle and they include in the network structure of curd (Mcsweeney et al., 2000), therefore, when the coagulant additive amount raised, lipases activity was influenced. Hexanoic acid has goat-like or animal-like odor (Mallia et al., 2005). The content of hexanoic acid was high in $0.5 \mathrm{X}$ cheese and it was low in $2 \mathrm{X}$ cheese.

\subsection{Influence of Coagulant Concentrate on hydrocarbons of Hard Cheese Made from Yak Milk}

Hydrocarbons are secondary products of lipid autoxidation and are precursors for the formation of aromatic compounds (Arora et al., 1995). Branched hydrocarbons such as 5-ethyl-2, 2, 3trimethyl-heptane and 6-methyl-octadecane were identified in the 0.5X cheese and 3-ethyl-2, 2dimethyl- Pentane and 5, 8-diethyl-dodecane were identified in the $\mathrm{X}$ cheese. Concentration of 2,2,4,6,6-pentamethyl- heptane was respectively $2.78 \%, 0.75 \%$ and $1.42 \%$ in the X,1.5 X and 2 X. 2, 2, 4, 6, 6-pentamethyl- heptane is found in Tulum cheese (Hayaloglu et al., 2007). Butylated hydroxytoluene was found in the $0.5 \mathrm{X}, 1.5 \mathrm{X}$ and $2 \mathrm{X}$ cheese except $\mathrm{X}$ cheese and its content was respectively $0.43 \%, 0.22 \%$ and $0.36 \%$. Hydrocarbons have been frequently reported in the volatile fraction of cheeses (Thierry et al., 1999; Carbonell, et al., 2002), although usually at low concentrations not detectable by olfactometry (Arora et al., 1995).

3.6Influence of Coagulant Concentrate on aldehydes and other compounds of Hard Cheese Made from Yak Milk

The aldehyde compounds identified in $\mathrm{X}$ cheese was3-hydroxylbutanal.In addition, 3 Methoxyamphetamine,4, 4,5,6 Tetramethyltetrahydro-1, 3 oxazin-2-thione and ethyl- hydrazine were identified in $0.5 \mathrm{X}$ cheese, 2-methyl-4- propyl- oxetane and 1, 3, 5-Trioxane were found in Xcheese and1-methylpentyl- hydroperoxide and 1-methylhexyl- hydroperoxide were found in 2X cheese.

\section{Conclusion}

Main volatile components in different cheese made from yak milk included esters, alcohols and acids, followed by hydrocarbons. With the increase of coagulant concentrate, number and content of volatile compounds gradually decreased and tended to stabilization. Esters were the first most abundant group of compounds and most of the identified esters were ethyl esters. Alcohols were the second most abundant group of compounds with ethanol which existed in all cheeses and 3methylbutanol which existed in all cheeses except for $0.5 \mathrm{X}$ cheese. Acids were the third most abundant group of compounds and from $0.5 \mathrm{X}$ to $2 \mathrm{X}$, acid species and content decreased. Only three volatile components were the same in the all of cheese and most of compounds are different among the cheese. Therefore, coagulant concentrate influenced on number and content of volatile components of hard cheese made from yak milk.

\section{References}

[1] Arora, G., Cormier, F., Lee, B.1995. Analysis of odor-active volatiles in Cheddar cheese headspace by multidimensional GC/MS/sniffing. Journal of Agricultural and Food Chemistry, 43(3):748-752. Barron, L., Redondo, Y., Aramburu, M., Pérez

Nájera, A. I., \& Renobales, M. D. 2005. Variations in volatile compounds and flavour in Idiazabal cheese manufactured from ewe's milk in farmhouse and factory. Journal of the Science of Food and Agriculture, 85(10): 1660-1671.

[2] Bills, D. D., Morgan, M. E., Libbey, L. M., \& Day, E. A. 1965. Identification of Compounds Responsible for Fruity Flavor Defect of Experimental Cheddar Cheeses 1, 2. Journal of dairy science, 48(9): 1168-1173.

[3] Broome, M. C., Krause, D. A., \& Hickey, M. W. 1990. The use of non-starter lactobacilli in Cheddar cheese manufacture. Australian Journal of Dairy Technology, 45(2): 67-73. 
[4] Carbonell, M., Nuñez, M., \& Fernández-García, E. 2002. Evolution of the volatile components of ewe raw milk La Serena cheese during ripening. Correlation with flavour characteristics. Le Lait, 82(6), 683-698.

[5] Hayaloglu, A. A., Cakmakci, S., Brechany, E. Y., Deegan, K. C., \& McSweeney, P. L. H. (2007). Microbiology, biochemistry, and volatile composition of Tulum cheese ripened in goat's skin or plastic bags. Journal of dairy science, 90(3), 1102-1121. Holmes, D. G., Duersch, J. W., \& Ernstrom, C. A. 1977. Distribution of Milk Clotting Enzymes between Curd and Whey and Their Survival during Cheddar Cheese Making 1, 4. Journal of Dairy Science, 60(6), 862-869.

[6] Liu, X.L., Gan, B. ZH. Li, F., Q, H.J., Niu, J., Song, X.2009. Processing technology of hard cheese from milk of white yak. Food Science, 30(14):94-98

[7] Liu, S. Q., Holland, R., \& Crow, V. L. 2004. Esters and their biosynthesis in fermented dairy products: a review. International Dairy Journal, 14(11): 923-945. McSweeney, P. L., \& Sousa, M. J. (2000). Biochemical pathways for the production of flavour compounds in cheeses during ripening: A review. Le Lait, 80(3):293-324.

[8] Ortigosa, M., Torre, P., \& Izco, J. M. 2001. Effect of pasteurization of ewe's milk and use of a native starter culture on the volatile components and sensory characteristics of Roncal cheese. Journal of dairy science, 84(6): 1320-1330.

[9] Panseri, S., Giani, I., Mentasti, T., Bellagamba, F., Caprino, F., \& Moretti, V.M., 2008. Determination of flavour compounds in a mountain cheeseby headspace sorptive extractionthermal desorption-capillary gaschromatography-mass spectrometry. LWT: Food Science and Technology 41 (2): 185-192

[10] Pionnier, E., Engel, E., Salles, C., \& Le Quere, J. L. 2002. Interaction between non-volatile water-soluble molecules andaroma compounds in Camembert cheese. Food Chemistry, 76: 1320

[11] Saldo, J., Fernández, A., Sendra, E., Butz, P., Tauscher, B., \& Guamis, B. 2003. High pressure treatment decelerates the lipolysis in a caprine cheese. Food research international, 36(9): 10611068.

[12] Suriyaphan, O., Drake, M. A., Chen, X. Q., \& Cadwallader, K. R. 2001. Characteristic aroma components of British farmhouse Cheddar. Journal of Agricultural and Food Chemistry, 49, $1382-1387$

[13] Thierry, A., Maillard, M. B., \& Le Quéré, J. L. 1999. Dynamic headspace analysis of Emmental aqueous phase as a method to quantify changes in volatile flavour compounds during ripening. International Dairy Journal, 9(7): 453-463.

[14] Yu, Q.L., Han, L.,Jiang Y.M.,Chen, Q.Y.,Shen, H.2005. Analysis of the nutritional components flavorous substances of white yak's milk. Acta Nutrimenta Sinica, 27(4):333-335

[15] Wang, Ch., Liang Q., Yang, M., Qiao H.J., Zhang Y. 2012. Determination of volatile components in yak's milk hard cheese by solid phase microextraction. Journal of Gansu Agricultural University, 47(2):141-146. 